\title{
Measurement of interleukin 10 in bronchoalveolar lavage from preterm ventilated infants
}

\author{
Janet R McColm, Ben J Stenson, Nienke Biermasz, Neil McIntosh
}

\begin{abstract}
Background-Interleukin 10 (IL-10) is a cytokine that downregulates inflammation, in part by reducing the production of the proinflammatory cytokines IL-1 $\beta$ and IL-8. It has been suggested that an inability to produce IL-10 might predispose preterm infants to develop chronic lung disease.

Aim-To measure IL-10, IL-1 $\beta$, and IL-8 in bronchoalveolar lavage fluid from ventilated preterm infants in a prospective cohort study.

Patients -17 consecutive newborn infants $\leqslant 29$ weeks' gestational age (median, 25; 9 boys) who were ventilated from birth underwent daily bronchoalveolar lavage sampling.

Results-102 samples were collected, of which 57 contained IL-10 in amounts that were comparable with those found previously in ventilated term infants with respiratory failure. Chronic lung disease developed in 9 of the 11 survivors and all 9 infants had produced IL-10. IL-1 $\beta$ and IL-8 were detected in nearly all samples and were raised throughout the course of sample collection.

Conclusion-IL-10 is readily detectable in early bronchoalveolar lavage samples from ventilated preterm infants, although it remains unclear whether this cytokine has any influence on the development of chronic lung disease.

(Arch Dis Child Fetal Neonatal Ed 2000;82:F156-F159)
\end{abstract}

Keywords: inflammation; cytokines; bronchopulmonary dysplasia; chronic lung disease; very preterm infants

During the past decade the outlook for infants born prematurely has improved steadily. Survival is now the most likely outcome and reducing the risk of long term morbidity such as chronic lung disease has become the major challenge. There is little to suggest that the incidence of chronic lung disease is falling, and some evidence suggests that the mean duration of ventilation and hospitalisation of the smallest infants has even been increasing. ${ }^{12}$ The pathogenesis of chronic lung disease is probably multifactorial, but it is increasingly clear that infants who go on to develop chronic lung disease have an early and persistent inflammatory response demonstrable within the lungs.

Inflammation is normally a tightly regulated but highly complex cascade of events in which cytokines act as the chemical messages between cells, responsible for both the promotion and downregulation of the inflammatory response. During the pulmonary inflammatory response, activated monocytes infiltrate the pulmonary interstitium from the blood and secrete the proinflammatory cytokines interleukin $1 \beta$ (IL$1 \beta$ ) and tumour necrosis factor $\alpha(\mathrm{TNF}-\alpha)$, which promote the upregulation of adhesion molecules on the pulmonary endothelium, ${ }^{3}$ and cause the release of chemokines such as IL- 8 and macrophage inflammatory protein $1 \alpha$ $(\mathrm{MIP}-1 \alpha)$. These chemokines promote the infiltration of circulating immune cells into the lungs. ${ }^{4}$ IL- $1 \beta$ and TNF- $\alpha$ also contribute to the downregulation of the inflammatory response by stimulating the release of IL-10 and transforming growth factor $\beta$ (TGF- $\beta$ ) from immune cells. IL-10 inhibits further TNF- $\alpha$, IL-1 $\beta$, and IL-8 release from both alveolar macrophages ${ }^{5}$ and neutrophils, ${ }^{6}$ and has been shown to be protective against immune complex induced lung disease. ${ }^{7}$ It also promoted neutrophil apoptosis in a model of pulmonary sepsis. ${ }^{8}$ TGF- $\beta$ prevents neutrophil migration by downregulating the expression of E-selectin on the endothelial cell surface, ${ }^{9}$ and directly inhibits the production of IL- 8 from endothelial cells. ${ }^{10}$ Therefore, IL-10 and TGF- $\beta$ might be important in modulating the pulmonary inflammatory response.

In infants who later develop chronic lung disease, raised concentrations of proinflammatory cytokines can be detected in the amniotic fluid before birth, ${ }^{11}$ and in bronchoalveolar lavage samples within hours of birth, ${ }^{12}{ }^{13}$ and these values remain high at $2-3$ weeks of age. ${ }^{12}{ }^{14}{ }^{15} \mathrm{In}$ addition, there is a rapid influx of large numbers of activated neutrophils into the airspaces within hours of birth. ${ }^{16}$ There are few data describing IL-10 concentrations in preterm infants, but it has been speculated recently that a relative inability of preterm infants to produce this anti-inflammatory cytokine might contribute to the pathogenesis of chronic lung disease. ${ }^{17} \mathrm{We}$ wished to investigate the production of IL-10 in mechanically ventilated preterm infants at risk of chronic lung disease.

\section{Patients and methods}

Seventeen consecutive infants admitted to a Scottish tertiary neonatal intensive care unit (NICU) were studied prospectively. All of the infants were intubated and ventilated immediately after birth and were enrolled in the study on the 1 st day of life. All of the infants received at least one dose of $100 \mathrm{mg} / \mathrm{kg}$ porcine surfactant (poractant $\alpha$; Chiesi Pharmaceutici, Italy) within a few hours of birth and were treated with antibiotics. None received corticosteroid treatment after birth during the study period. Chronic lung disease was defined as a 
requirement for supplemental oxygen at 36 weeks' corrected gestational age. ${ }^{18}$

SAMPLE COLLECTION

All samples were collected during routine endotracheal suction, which was being performed for clinical reasons. After instillation of $0.5 \mathrm{ml}$ saline, the ventilator was reconnected for three to four breaths and then a suction catheter (6 French gauge) was pushed down the endotracheal tube until resistance to the advance of the catheter was felt. Suction was applied and the aspirated material was collected in a trap. The first sample was taken as soon as possible after birth, on the 1st day of life. Subsequent samples were taken daily until day 10 from those infants who remained ventilated. Sanction for this sampling was gained from the hospital ethics research committee.

SAMPLE PROCESSING

Samples were flushed from the mucous trap using RPMI 1640 medium (South East Blood Transfusion Service, Edinburgh, UK) and mucus was removed by straining the sample through a cell strainer (pore size, $70 \mu \mathrm{m}$ ). The cells were removed by centrifugation at $400 \times g$ for 10 minutes. The supernatant was aliquoted and immediately frozen at $-70^{\circ} \mathrm{C}$. The cell pellet was resuspended in RPMI 1640 medium, the cells were counted, and their viability was assessed by trypan blue exclusion. The cell suspension was adjusted to $1 \times 10^{6}$ cells $/ \mathrm{ml}$ and $100 \mu$ of suspension was added to a cytospin slide (Shandon cytospin 3; Shandon Scientific Ltd, UK). The slide was stained differentially (Diff Quick; Dade Behring Ltd, UK) and differential cell counts were performed on 300 cells.

CYTOKINE ASSAYS

Owing to constraints of sample volume it was only possible to measure three cytokines in each sample. IL- 8 was measured by an in house radioimmunoassay (detection limit of $50 \mathrm{pg} /$ $\mathrm{ml}$, intra-assay variation of $<5 \%$, interassay variation of $<13 \%)$. IL- $1 \beta$ and IL-10 were measured by high sensitivity enzyme linked immunosorbent assay (R\&D Systems Europe Ltd, UK); ranges were $0.125-8 \mathrm{pg} / \mathrm{ml}$ and $0.78-50 \mathrm{pg} / \mathrm{ml}$, respectively. Values were expressed as weight of cytokine/volume of lavage fluid.

\section{Results}

Table 1 details the characteristics at study onset of the 17 enrolled infants. The ventilation strategy was determined by the clinical staff and was not part of the study protocol. High frequency oscillatory ventilation was used from the time of admission to the NICU in 16 infants. One infant was treated initially with conventional ventilation and switched to high frequency oscillatory ventilation after 24 hours. The infants spent a median seven days (interquartile range, 5-8.5 days) on high frequency oscillatory ventilation before being switched to conventional ventilation until extubation. Of the 17 infants enrolled in the study, six died before 36 weeks' corrected gestational
Table 1 Clinical characteristics

\begin{tabular}{ll}
\hline Total number & $17(9$ boys $)$ \\
Gestation (weeks) & $25(23-29)^{\star}$ \\
Birth weight $(\mathrm{g})$ & $700(530-1430)^{\star}$ \\
Antenatal steroids & 15 \\
Premature rupture of membranes & 5
\end{tabular}

${ }^{\star}$ Median (range)

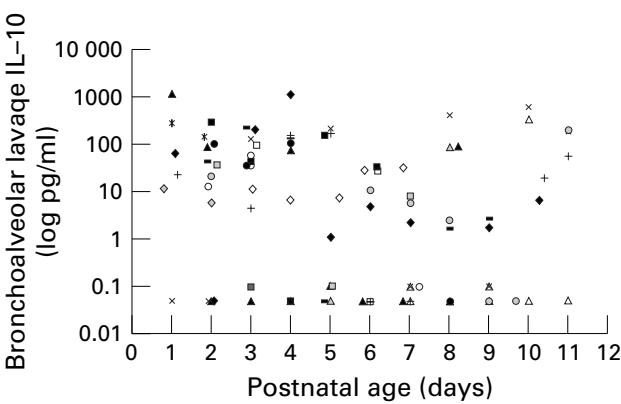

Figure 1 Bronchoalveolar lavage interleukin 1 (IL-10) (pg/ml) over the first 10 days of life for all infants in our study. A different symbol is used for each infant. Samples in which IL-10 was undetectable are plotted at the lower limit of detection of the assay $(0.78 \mathrm{pg} / \mathrm{ml})$.

age and nine of the 11 surviving infants developed chronic lung disease. The two survivors who did not develop chronic lung disease were extubated at 6 and 8 days of age, respectively. We obtained 102 bronchoalveolar lavage specimens suitable for analysis from 17 infants during their first 10 days of life. IL-10 was detectable in $56 \%$ of the specimens. The values ranged from 0 to $1170 \mathrm{pg} / \mathrm{ml}$ with a mean of $167 \mathrm{pg} / \mathrm{ml}$ (95\% confidence intervals, 128206). Figure 1 shows the IL-10 concentrations plotted against time for all 17 of the infants enrolled in our study. All except one of the 17 infants had measurable IL-10 at some point during the study period, although there was a wide range of concentrations, both within infants over time and between infants. IL-10 was readily detectable on days $1-4$ and $10-12$ but was present in smaller amounts between days 5-9. All five of the bronchoalveolar lavage samples obtained from the two survivors who did not develop chronic lung disease contained IL-10. The nine surviving infants who developed chronic lung disease had measurable IL-10 in $57 \%$ of the 72 bronchoalveolar lavage specimens obtained from them. Figure 2 shows the cell counts from the bronchoalveolar lavage specimens. The total cell counts were high during the first 96 hours of life and then gradually decreased with time. The samples taken on the 1st day of life consisted mainly of epithelial cells and these were not plotted. After day 1 , neutrophils predominated and were the most frequently identified cell type at most time points. Total neutrophil numbers decreased after 96 hours, so that although the absolute number of macrophages did not increase greatly, their proportion of the total cell count did.

Figure 3 shows the concentrations of IL- $1 \beta$ and IL- 8 found in all 17 of the infants. The concentrations of both cytokines fell during the first 24 hours of life before climbing for the next 72 hours and then remaining high for the rest of the study. The highest concentrations of 


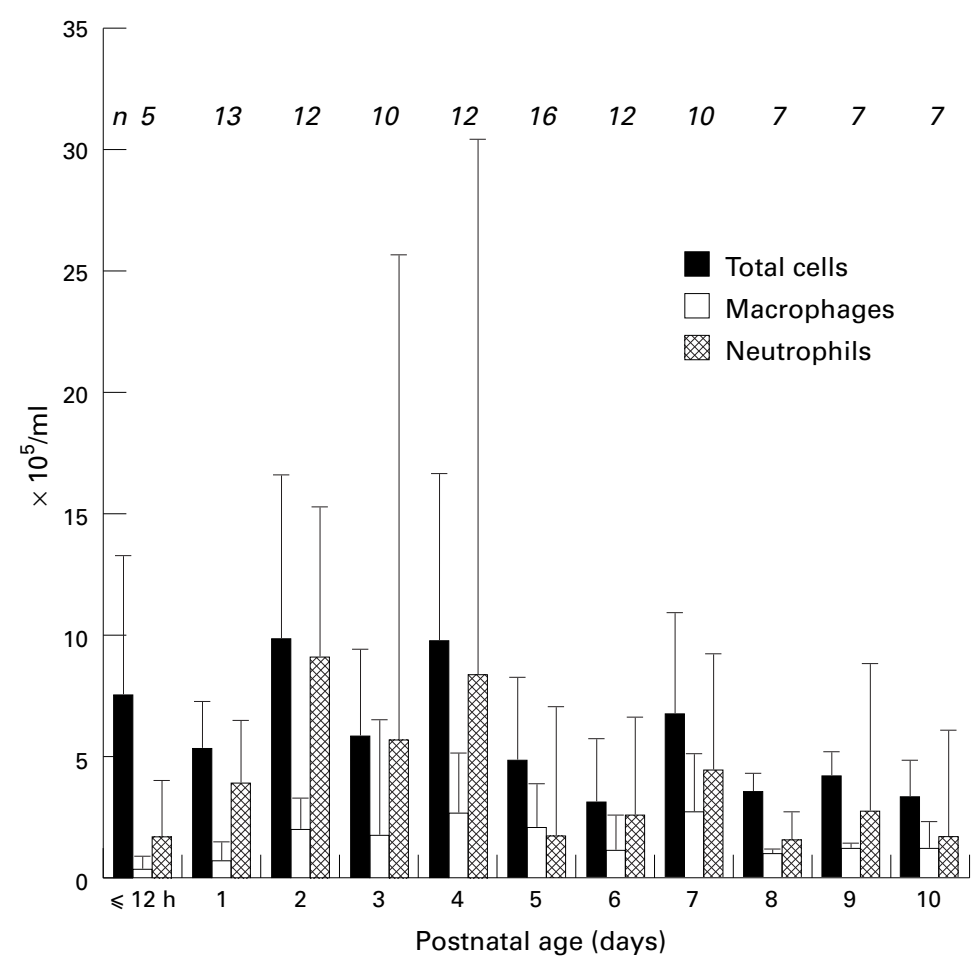

Figure 2 Total cell counts, neutrophils, and macrophages in bronchoalveolar lavage over the first 10 days of life for all infants. Data are medians (+ interquartile ranges). n, number of samples summarised at each time point.

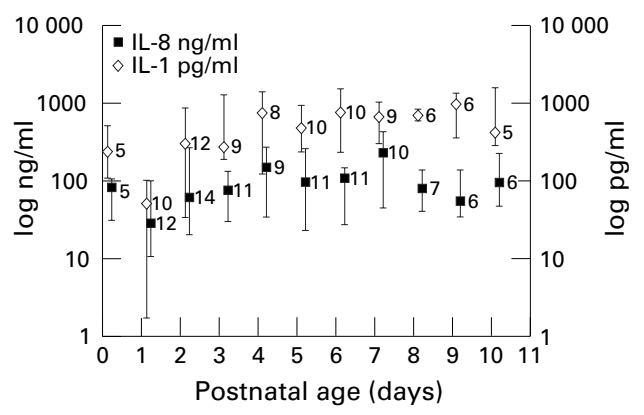

Figure 3 Bronchoalveolar lavage interleukin $1 \beta$ (IL-1) $(\mathrm{pg} / \mathrm{ml})$ and $\mathrm{IL}-8(\mathrm{ng} / \mathrm{ml})$ over the first 10 days of life for all infants in our study. Data are medians ( \pm interquartile ranges). The number of samples summarised at each time point is shown to the right of each point on the graph.

IL-8 were found on day 7 , coinciding with the period of time that IL-10 was almost undetectable. There were no significant correlations between IL-8, IL-1 $\beta$, and IL-10.

\section{Discussion}

IL-10 was detectable in bronchoalveolar lavage samples from 16 of 17 ventilated preterm infants in our study at concentrations similar to those previously seen in ventilated term infants with acute respiratory failure. ${ }^{17}$ Sustained rises in proinflammatory mediators have been implicated in the pathogenesis of chronic lung disease, ${ }^{121415}$ and Jones et al have suggested recently that an inability of preterm infants to counterbalance this inflammation by producing the downregulatory cytokine IL-10 might also be an important factor. ${ }^{17}$ Jones et al were rarely able to detect either IL-10 protein or IL-10 mRNA in bronchoalveolar lavage specimens from ventilated preterm infants with hyaline membrane disease, using methods that were able to detect both IL-10 protein and mRNA in ventilated term infants with respiratory failure. They measured samples taken from five preterm infants during their first 96 hours of life, whereas we assayed specimens from 17 infants during the first 10 postnatal days. Although individually the infants in our study had variable IL-10 production, all except one produced measurable amounts of IL-10 at some point in the first 10 days of life.

Jones et al performed two bronchoalveolar lavage procedures using $1.5 \mathrm{ml}$ of saline each time and pooled the two aspirates. We performed a single $0.5 \mathrm{ml}$ bronchoalveolar lavage procedure on each occasion, so it is possible that different sampling techniques could account for some of the difference in results between the two studies. In both studies, cytokine concentrations were expressed as weight of cytokine/ $\mathrm{ml}$ of bronchoalveolar lavage fluid. Measurements expressed in this manner may vary according to the proportion of the lavage material that was saline. Efforts have been made to find alternative methods for correcting for sample dilution using various reference markers but these are controversial. ${ }^{19}{ }^{20}$ In particular, it is claimed that secretory component is independent of pulmonary leak, gestational age, and postnatal age. ${ }^{21}$ However Groneck and colleagues $^{15}$ showed that the bronchoalveolar lavage fluid secretory component concentration was significantly lower on the 1 st day of life than on other days, and it has also been shown that this marker is upregulated by TNF- $\alpha,{ }^{22}$ which has previously been measured in similar samples. ${ }^{14}$ Albumin cannot be used because it increases in some disease states, ${ }^{23}$ can be affected by treatment, ${ }^{24}$ and increases in serum with postnatal age. ${ }^{21}$ Urea almost certainly moves into the lavage fluid from the plasma during the bronchoalveolar lavage procedure by diffusion down a concentration gradient ${ }^{25}$ and is unsuitable. Therefore, values are expressed as weight/volume of lavage fluid.

Although IL-8 production remained fairly constant for each individual, IL-10 production was highly variable. Our results show a trend towards high IL-8 concentrations at times when IL-10 was virtually undetectable (days 5-8), although there was no significant correlation seen overall between the concentrations of the two cytokines. It is possible that an imbalance between the cytokines could be a predisposing factor to chronic lung disease. IL-8 can be measured in these samples in concentrations of $\mathrm{ng} / \mathrm{ml}$, whereas IL-10 is only detectable in $\mathrm{pg} / \mathrm{ml}$. It is not known what constitutes a physiologically relevant concentration of either of these cytokines in vivo, or what effect their relative values might have on effector cells.

At present, there is little evidence that IL-10 is an important anti-inflammatory cytokine in the pathogenesis of chronic lung disease. IL-10 knockout mice do not develop spontaneous lung disease, although they do manifest chronic enterocolitis, probably as a result of an inability to downregulate inflammation in the gut. ${ }^{26}$ This is in contrast to TGF- $\beta$ knockout mice, which by the second postnatal week develop 
multifocal inflammatory disease, resulting in fatal cardiopulmonary complications. ${ }^{27} 28$ TGF- $\beta$ knockout mice also express increased TNF- $\alpha$ and MIP- $1 \alpha$ mRNA in their lungs, and their monocytes and immature neutrophils are hyperresponsive. ${ }^{27}$ Preterm baboons delivered at 125 days' gestation, during the canalicular stage of lung development, given exogenous surfactant and ventilated with oxygen and tidal volume sparing treatment strategies, develop chronic lung disease similar to that seen in preterm human infants. During the course of their intensive care, these preterm baboons produce similar amounts of IL-10 to those found in term infants and adults, ${ }^{29}$ and similar to those measured in our preterm infants.

Bronchoalveolar lavage samples are only available in our unit when endotracheal suction is clinically indicated because our clinical staff believe that this procedure is distressing to infants. Because of this policy we did not always manage to obtain a sample at all time points in our study. We collected one sample daily and found our results to be highly variable. It might be that studies examining the results of serial samples taken over a shorter time interval would give a clearer picture of the variability in values and whether this is an important factor. However, primate models have shown that repeated sampling over time can damage lungs, ${ }^{30}$ making it ethically difficult to pursue this line of research. All of the infants in our study had received porcine surfactant early in life. This has been shown to have a variety of anti-inflammatory properties, including inhibition of monocyte TNF- $\alpha,{ }^{31}$ and it is possible that this might also have some influence on IL-10 production.

Most of the surviving infants in our study developed chronic lung disease. This was a very immature population of infants, whose median gestational age was 25 weeks and birth weight $700 \mathrm{~g}$, who were therefore at high risk for adverse outcome. Because most of the infants developed chronic lung disease we are unable to relate our IL-10 results to the risk of this outcome. At present, there are no published data that examine this issue directly. It may be that infants of comparable gestational age that have good clinical outcomes differ in their IL-10 production. Further studies will be required to determine whether this is so.

CONCLUSIONS

IL-10 is present in bronchoalveolar lavage samples from preterm infants, but the influence of IL-10 on the pathogenesis of chronic lung disease remains to be elucidated.

The authors thank the staff at the neonatal unit for their help in collecting bronchoalveolar lavage samples.

1 Field DJ, Milner AD, Hopkin IE, Madeley RJ. Changing patterns in respiratory distress syndrome. Pediatr Pulmonol 1987;3:231-5.

2 Horbar JD, Wright EC, Onstad L. Decreasing mortality associated with the introduction of surfactant therapy: an observational study of neonates weighing 601 to 1300 grams at birth. Pediatrics 1993;92:191-6.

3 Brown EJ. Adhesive interactions in the immune system. Trends Cell Biol 1997; 7:289-95.

4 Merrit TA, Stuard ID, Puccia J, et al. Newborn tracheal aspirate cytology: classification during respiratory distress syndrome and bronchopulmonary dysplasia. $\mathcal{F}$ Pediat 1981;98:949-56. 5 Thomassen MJ, Divis LT, Fisher CJ. Regulation of human alveolar macrophage inflammatory cytokine production by 6 Cassatella MA, Meda L, Bonora S, Ceska M, Constantin G. IL-10 inhibits the release of proinflammatory cytokines from human polymorphonuclear leucocytes: evidence for an autocrine role of tumour necrosis factor and IL-1b in mediating the production of IL-8 triggered by lipopolysaccharide. $\mathcal{F}$ Exp Med 1993;178:2207-11

7 Mulligan MS, Jones ML, Vaporciyan AA, Howard MC, Ward PA. Protective effects of IL- 4 and IL-10 against immune complex-induced lung injury. $\mathcal{f}$ Immunol 1993;151:5666-74

8 Bonfield TL, Konstan MW, Burfeind P, Panuska JR, Hilliard JB, Berger M. Normal bronchial epithelial cells constitutively produce the anti-inflammatory cytokine interleukin-10, which is downregulated in cystic fibrosis. Am F Respir Cell Mol Biol 1995;13:257-61.

9 Gamble JR, Khew-Goodall Y, Vadas MA. Transforming growth factor-beta inhibits E-selectin on human endothegrowth factor-beta inhibits E-selectin

10 Smith WB, Noack L, Khew-Goodall Y, Isenmann S, Vadas MA, Gamble JR. Transforming growth factor-beta1 inhibits the production of IL- 8 and the transmigration of neutrophils through activated endothelium. F Immunol 1996;157:360-8.

11 Ghezzi F, Gomez R, Romero R, et al. Elevated interleukin-8 concentrations in amniotic fluid of mothers whose neonates subsequently develop bronchopulmonary dysplasia. Eur 7 Obstet Gynecol Reprod Biol 1998;78:5-10.

12 Murch SH, Costeloe K, Klein NJ, MacDonald TT. Early production of macrophage inflammatory protein 1 alpha
occurs in respiratory distress syndrome and is associated occurs in respiratory distress syndrome and is
with poor outcome. Pediatr Res 1996;40:490-7.

13 McColm JR, McIntosh N. Interleukin-8 in bronchoalveolar lavage samples as predictor of chronic lung disease in premature infants. Lancet 1994:343:729.

14 Murch S, MacDonald TT, Wood CBS, Costeloe KL. Tumour necrosis factor in the bronchoalveolar secretions of infants with the respiratory distress syndrome and the effect of dexamethasone treatment. Thorax 1992;47:44-7.

5 Groneck P, Gotze-Speer B, Opperman M, Eiffert H, Speer CP. Association of pulmonary inflammation and increased microvascular permeability during the development of bronchopulmonary dysplasia: a sequential analysis of inflammatory mediators in respiratory fluids of high-risk preterm neonates. Pediatrics 1994;93:712-18.

16 Arnon S, Grigg J, Silverman M. Pulmonary inflammatory cells in ventilated preterm infants: effect of surfactant treatment. Arch Dis Child 1993;69:44-8.

17 Jones CA, Cayabyab RG, Kwong KYC, et al. Undetectable interleukin-10 and persistent IL-8 expression early in hyaline membrane disease: a possible developmental basis for line membrane disease: a possible developmental basis for the predisposition to chronic lung inflamm
preterm newborns. Pediatr Res 1996;39:966-75.

18 Shennan AT, Dunn MS, Ohlsson A, Lennox K, Hoskins EM. Abnormal pulmonary outcomes in premature infants: prediction from oxygen requirement in the neonatal period. Pediatrics 1988;82:527-32.

19 Klech H, Pohl W. Technical recommendations and guidelines for bronchoalveolar lavage (BAL). Eur Respir 7 1989;2:561-85.

20 Walters EH, Gardiner PV. Bronchoalveolar lavage as a research tool. Thorax 1991;46:613-18.

21 Watts CL, Bruce MC. Comparison of secretory component for immunoglobulin A with albumin as reference proteins in tracheal aspirate from preterm infants. If Pediatr 1995;127:113-22.

22 Kvale D, Lovhaug D, Sollid M, Brandtzaeg P. Tumour necrosis factor upregulates expression of secretory component, the epithelial receptor for polymeric immunoglobulins. F Immunol 1988;140:3086-90.

23 Jones KP, Edwards JH, Reynolds SP, Peters TJ, Davies BH. A comparison of albumin and urea as reference markers in bronchoalveolar lavage fluid from patients with interstitial lung disease. Eur Respir $\mathcal{F}$ 1990;3:152-6.

24 Duddridge M, Ward C, Williams S, et al. Albumin as a disease activity marker in lavage (BAL) fluid in sarcoidosis and asthma patients treated with steroids. Thorax 1990;45:799-800.

25 Marcy TW, Merril WW, Rankin JA, Reynolds HY. Limitations of using urea to quantify epithelial lining fluid recovered by bronchoalveolar lavage. Am Rev Respir Dis 1987;135:1276-80.

26 Kuhn R, Lohler J, Rennick D, Rajewsky K, Muller W. Interleukin-10-deficient mice develop chronic enterocoliInterleukin-10-deficient
tis. Cell 1993;75:263-74.

27 Shull MM, Ormsby I, Kier AB, et al. Targeted disruption of the mouse transforming growth factor-beta 1 gene results in multifocal inflammatory disease. Nature 1992;359:693-9.

28 Kulkarni AB, Karlsson S. Transforming growth factor-beta 1 knockout mice. A mutation in one cytokine gene causes a
dramatic inflammatory disease. Am f Pathol 1993;143:3-9.

29 Coalson JJ, Winter VT, Siler-Khodr T, Yoder BA. Neonatal chronic lung disease in extremely immature baboons. Am $\exists$ Respir Crit Care Med 1999;160:1333-46.

30 Krombach F, Fiehl E, Burkhardt D, et al. Short-term and long-term effects of serial bronchoalveolar lavages in a nonhuman primate model. Am $\mathcal{F}$ Respir Crit Care Med 1994;150:153-8.

31 Speer CP, Götze B, Curstedt T, Robertson B. Phagocytic functions and tumour necrosis factor secretion of human monocytes exposed to natural porcine surfactant (Curosurf). Pediatr Res 1991;30:69-74. 